\title{
Bilophila wadsworthia, gen. nov. and sp. nov., a Unique Gram-negative Anaerobic Rod Recovered from Appendicitis Specimens and Human Faeces
}

\author{
By ELLEN J. BARON, 1.2,3* PAULA SUMMANEN, ${ }^{1,2}$ \\ JULIE DOWNES, ${ }^{1,2}$ MARILYN C. ROBERTS, ${ }^{4}$ HANNAH WEXLER ${ }^{2,3}$ \\ AND SYDNEY M. FINEGOLD ${ }^{1,2,3}$ \\ ${ }_{1.2}$ Clinical Anaerobic Bacteriology Research Laboratory ${ }^{1}$ and Research Service, \\ V. A. Wadsworth Medical Center, Wilshire and Sawtelle Blvds, Los Angeles, CA 90073, USA \\ ${ }^{3}$ Department of Medicine, UCLA School of Medicine, Los Angeles, CA 90024, USA \\ ${ }^{4}$ Department of Pathobiology, University of Washington, Seattle, WA 98195, USA
}

(Received 29 March 1989; revised 7 July 1989; accepted 28 July 1989)

Strongly catalase-positive Gram-negative anaerobic rods were isolated from approximately half of all intra-abdominal specimens received from patients with gangrenous and perforated appendicitis, and subsequently also from normal faecal specimens. The organism was originally detected on Bacteroides-bile-aesculin (BBE) agar, and grew slowly on non-selective anaerobic media containing blood. It was stimulated by bile and differed from other known genera by being urease- and catalase-positive, and by reducing nitrate. It did not reduce sulphate. Other anaerobic Gram-negative rods showed no homology by DNA dot-blot hybridization. The thermal melting profile of chromosomal DNA showed $39-40 \mathrm{~mol} \% \mathrm{G}+\mathrm{C}$. The whole-cell fatty acid methyl ester profile included cyclic and branched long-chain acids, and differed from those of all other anaerobes that have been tested. $\beta$-Lactamase was not detected. The name Bilophila wadsworthia gen. nov., sp. nov. is proposed for this organism.

\section{INTRODUCTION}

Human faeces contain as many as $10^{11}$ c.f.u. of bacteria per gram (Finegold et al., 1974; Holdeman et al., 1976; Moore \& Holdeman, 1974). Anaerobes outnumber aerobes by about $1000: 1$ in the bowel (Finegold, 1977); however, relatively few species seem to predominate in intra-abdominal infections. Most previously published studies of the bacteriology of appendiceal infections report recovery of three to six species of bacteria per specimen, with anaerobes (particularly the Bacteroides fragilis group) predominating (Werner \& Seeliger, 1963; David et al., 1982; Berne et al., 1982; Pieper et al., 1979; Lau et al., 1984). In a recent study, cultures of perforated and gangrenous appendix and peritoneal fluid or pus specimens yielded an average of 11 organisms per specimen, with an average of seven anaerobes per specimen (Bennion et al., 1989). During that study, a novel bacterium was isolated from approximately half of all specimens. Because this organism is believed to be significantly different from other described genera, the name Bilophila wadsworthia gen. nov., sp. nov. is proposed.

\section{METHODS}

Bacterial strains. A homogeneous collection of strains of bile-resistant, catalase-positive, slow-growing Gramnegative bacilli was isolated from peritoneal fluid (14 strains), abdominal abscess aspirates (four strains), or gangrenous appendiceal tissue (nine strains) obtained at surgery during the course of a study to define the bacterial flora of infection related to perforated and gangrenous appendicitis. Fluid specimens were injected into an anaerobic transport vial (Port-a-Cul vial, BBL Microbiology Systems) and tissue biopsies, made by removing a

Abbreviations: BBE medium, Bacteroides-bile-aesculin medium; PRAS, pre-reduced, anaerobically sterilized. 
tangential slice of the appendiceal wall so as to avoid luminal contents, were placed into a sterile $17 \times 100 \mathrm{~mm}$ snap-top plastic tube (Falcon, Becton-Dickinson) which was immediately sealed into a self-generating anaerobic pouch (GasPak Pouch, BBL). The cap of the tube was left loose until the methylene blue indicator in the pouch indicated anaerobic conditions. Specimens were kept at room temperature until they were cultured, usually within $18 \mathrm{~h}$ of collection.

Tissues were ground in plastic disposable tissue grinders (Sage Products) in measured amounts of supplemented fluid thioglycollate medium (Anaerobe Systems). Known quantities of vortexed tissue suspensions or fluid specimens were inoculated onto supplemented Brucella blood agar without cysteine, phenylethyl alcohol agar, kanamycin-vancomycin agar with laked sheep blood, and Bacteroides-bile-aesculin (BBE) agar, and into fluid thioglycollate medium (all obtained from Anaerobe Systems) in addition to routine aerobic media. All manipulations were carried out in an atmosphere of $\mathrm{N}_{2} / \mathrm{CO}_{2} / \mathrm{H}_{2}(80: 10: 10$, by vol.) within an anaerobic chamber (Coy Laboratories). Initial incubation took place in the chamber at $35^{\circ} \mathrm{C}$. Plates were examined after $48 \mathrm{~h}$ incubation and on two or three other occasions for up to $14 \mathrm{~d}$. Different colony morphotypes seen on each agar were isolated for further studies (Bennion et al., 1989).

During this study, a series of isolates that shared colony morphology characteristics and initial rapid test results (particularly a strongly positive catalase) were recognized. On further testing, these bile-resistant, strongly catalase-positive, pyruvate-stimulated strains were found to comprise a single, homogeneous group of organisms. Data from 27 strains are presented here.

The Bacteroides species used for comparative purposes included the proposed type strain for each species listed by Holdeman et al. (1984). These included Bacteroides (now Porphyromonas) asaccharolyticus ATCC 25260, B. bivius ATCC 29303, B. buccae ATCC 33574, B. capillosus ATCC 33690, B. corporis ATCC 33547, B. disiens ATCC 29426, B. distasonis ATCC 8503, B. eggerthii ATCC 27754, B. fragilis ATCC 25285, B. (now Porphyromonas) gingivalis ATCC 33277, B. intermedius ATCC 25611 , B. loescheii ATCC 15930, B. melaninogenicus ATCC 25845, B. multiacidus (now Mitsuokella multiacidus) ATCC 27723, B. oris ATCC 33573, B. ovatus ATCC 8483, B. splanchnicus ATCC 29572, B. thetaiotaomicron ATCC 29148, B. uniformis ATCC 8492 , B. ureolyticus ATCC 33387 and B. vulgatus ATCC 8482. Desulfomonas pigra ATCC 29098 and Desulfovibrio desulfuricans ATCC 7757 were also studied. All strains were obtained from the American Type Culture Collection, Rockville, Maryland, USA, and authenticity was verified biochemically (Roberts et al., 1987). For biochemical studies, strains were stored frozen in double-strength skim milk (Difco), passed on supplemented Brucella blood agar without cysteine (BBL), and tested from subcultures on Brucella blood agar.

Biochemical and morphological characterization. After initial isolation, the organisms were subcultured on the open bench and incubated in anaerobic GasPak jars (BBL). Identification procedures, including biochemical tests, gas-liquid chromatography, and additional studies, were those described in the Wadsworth and VPI Anaerobe Manuals (Sutter et al., 1985; Holdeman et al., 1977). Screening tests included inhibition by specialpotency antibiotic disks (vancomycin $5 \mu \mathrm{g}$, kanamycin $1000 \mu \mathrm{g}$ and colistin $10 \mu \mathrm{g}$; BBL), inhibition by $20 \%$ bile disks (Remel), catalase production $\left(15 \%, \mathrm{v} / \mathrm{v}, \mathrm{H}_{2} \mathrm{O}_{2}\right)$, and spot indole and nitrate reactions. Hydrogen sulphide production was detected in pre-reduced, anaerobically sterilized (PRAS) SIM medium (Scott Laboratories). Urease production was detected in urease broth concentrate diluted 1:10 (Difco). Initial determination of presence of desulphoviridin was done as described by Holdeman et al. (1977). Tests for fermentation reactions, metabolic endproducts, nitrate reduction, indole production, bile stimulation, and aesculin and gelatin hydrolysis were carried out using PRAS media (Carr-Scarborough). All broth media were supplemented with $1 \%$ ( $w / v)$ pyruvate. $\beta$-Lactamase was determined using a chromogenic cephalosporin spot test (Cefinase, BBL).

DNA extraction and purification. Each strain was grown on agar plates at $37^{\circ} \mathrm{C}$ in an anaerobic atmosphere. The DNA extraction method was as described previously for Mobiluncus species (Spiegel \& Roberts, 1984). Briefly, strains were harvested from Brucella agar plates into TE (0.15 M-Tris, $0.1 \mathrm{M}$-EDTA, pH 8.0). Lysozyme was added to a final concentration of $1.0 \mathrm{mg} \mathrm{ml}^{-1}$. The suspension was treated with pronase (Sigma) and SDS $(0.4 \%$, $\mathrm{w} / \mathrm{v}$ ) to induce cell lysis. The suspension was further diluted in TE, treated overnight with proteinase K (Sigma), mixed with an equal volume of Tris-saturated phenol, and centrifuged. The aqueous phase, mixed with an equal volume of chloroform, was centrifuged, re-extracted with chloroform, and the DNA was precipitated with $0.3 \mathrm{M}$-sodium acetate and cold ethanol. After a final centrifugation, the pellet was resuspended in $0.1 \times \operatorname{SSC}(1 \times$ SSC is $0.15 \mathrm{M}-\mathrm{NaCl}$ plus $0.015 \mathrm{M}$-sodium citrate $\mathrm{pH} \mathrm{7.0)}$ and $\mathrm{NaCl}$, EDTA and Tris were added to final concentrations of $0.1 \mathrm{mM}, 0.05 \mathrm{mM}$ and $0.025 \mathrm{~mm}$, respectively. Boiled ribonuclease (Sigma) was added, and the DNA was extracted twice with chloroform/isoamyl alcohol $(24: 1, \mathrm{v} / \mathrm{v})$ and precipitated with sodium acetate and cold ethanol. After suspension in $0 \cdot 1 \times \mathrm{SSC}$, the DNA was dialysed against $0.42 \mathrm{M}-\mathrm{NaCl}$.

DNA dot-blots. DNA $(0.1 \mu \mathrm{g})$ was nick-translated as described previously (Roberts et al., 1987) using two ${ }^{32} \mathrm{P}$-labelled nucleoside triphosphates and two unlabelled nucleoside triphosphates. The unincorporated radiolabel was separated from the labelled double-stranded DNA by passage through a $15 \mathrm{~cm}$ Sephadex G-75 column. The probes were stored at $-10^{\circ} \mathrm{C}$ and used within one week. Pure DNA (5-15 $\left.\mu \mathrm{g}\right)$ was spotted onto nitrocellulose, which was treated to fix the DNA to the nitrocellulose and stored at room temperature until needed (Roberts et al., 1987). The nitrocellulose was hybridized overnight at $42{ }^{\circ} \mathrm{C}$ under stringent conditions of $50 \%$ (v/v) 
formamide, $0 \cdot 1 \%(w / v)$ polyvinylpyrrolidone, $0 \cdot 1 \%(w / v)$ albumin, $0 \cdot 1 \%(w / v)$ Ficoll, $0 \cdot 1 \%(w / v)$ SDS, $0.05 \mathrm{M}-\mathrm{NaH}_{2} \mathrm{PO}_{4}$ (pH 7.4), $0.005 \mathrm{M}-\mathrm{EDTA}, 0.76 \mathrm{M}-\mathrm{NaCl}$ and $100 \mu \mathrm{g}$ boiled calf thymus DNA ml ${ }^{-1}$. The filters were then removed and washed three times for $10 \mathrm{~min}$ each at $52^{\circ} \mathrm{C}$ in $0 \cdot 1 \% \operatorname{SDS} / 0 \cdot 1 \times \mathrm{SSC}$, followed by three 10 min washes at $52^{\circ} \mathrm{C}$ in $0.1 \times \mathrm{SSC}$. The washed filters were dried, exposed to Kodak X-omat AR film at $-70^{\circ} \mathrm{C}$ and developed.

Determination of thermal melting profiles. DNA from two strains of the novel bacterium along with an Escherichia coli control (strain $\mathrm{HB101} ; \mathrm{G}+\mathrm{C}$ content $51 \mathrm{~mol} \%$ ) were dialysed against 4 litres of $0.5 \times \mathrm{SSC}$. The melting profiles were determined as described by Johnson (1981) using a Gilford model 250 automatic recording spectrophotometer equipped with a heated cuvette holder. $E$. coli $\mathrm{HB} 101$ was used as an internal standard for each experiment. Analyses were performed in triplicate over a one week period.

Cellular fatty acid determination. Fatty-acid methyl esters of whole-cell extracts were determined according to the method of Moss \& Nunez-Montiel (1982). Briefly, cells were harvested from growth on supplemented brain heart infusion agar with $5 \%(\mathrm{v} / \mathrm{v})$ sheep blood (Carr-Scarborough) after $48 \mathrm{~h}$ incubation at $35^{\circ} \mathrm{C}$, saponified in $\mathrm{NaOH}$ in aqueous methanol, methylated in hydrochloric acid in aqueous methanol, extracted in hexane and methyl-tert-butyl ether, washed in dilute $\mathrm{NaOH}$, and analysed in a gas-liquid chromatograph (Hewlett-Packard $5890 \mathrm{~A}$ ) equipped with a silicone-lined capillary column using the Microbial ID software package. The fatty acids were identified by comparing their retention times with those of Standards.

Tests for sulphate reduction. Sulphate reduction was determined in aqueous liquid medium containing $0.05 \%$ $(\mathrm{w} / \mathrm{v}) \mathrm{KH}_{2} \mathrm{PO}_{4}, 0.05 \%$ (w/v) $\mathrm{NH}_{4} \mathrm{Cl}, 0.3 \%$ (w/v) $\mathrm{Na}_{2} \mathrm{SO}_{4}, 0.05 \%(\mathrm{w} / \mathrm{v}) \mathrm{MgSO}_{4} .6 \mathrm{H}_{2} \mathrm{O}, 0.01 \%(\mathrm{w} / \mathrm{v}) \mathrm{CaCl}_{2} .2 \mathrm{H}_{2} \mathrm{O}$, $1.0 \%(\mathrm{w} / \mathrm{v})$ sodium pyruvate, $0.1 \%(\mathrm{w} / \mathrm{v})$ yeast extract, $0.01 \%(\mathrm{w} / \mathrm{v})$ ascorbic acid and $0.01 \%(\mathrm{w} / \mathrm{v})$ sodium thioglycollate $\left(\mathrm{pH} \mathrm{7.4)}\right.$. Filter-sterilized solutions $\left(0.22 \mu \mathrm{m}\right.$ pore-size filters) of 4-aminobenzoic acid $\left(8 \mathrm{mg} \mathrm{l}^{-1}\right)$, $\mathrm{D}(+)$ biotin $\left(2 \mathrm{mg} \mathrm{l}^{-1}\right)$, nicotinic acid $\left(20 \mathrm{mg} \mathrm{l}^{-1}\right)$ and calcium $\mathrm{D}(+)$ pantothenate $\left(10 \mathrm{mg} \mathrm{l}^{-1}\right)$ were prepared as stock growth-supplement solutions and added to the sulphate reduction test medium before inoculation ( $5 \mathrm{ml}$ stock solution per litre of medium). After sufficient growth of organism had occurred in the test medium, $2.0 \mathrm{ml}$ copper sulphate reagent $\left(5 \mathrm{~mm}-\mathrm{CuSO}_{4}\right.$ in $\left.50 \mathrm{mM}-\mathrm{HCl}\right)$ was added to $0.5 \mathrm{ml}$ culture. The presence of a brown-black precipitate indicated production of hydrogen sulphide.

Electron microscopy. Organisms were concentrated by centrifugation after $48 \mathrm{~h}$ growth in broth. Thin-section preparation, negative staining, and freeze-fracture preparations were performed as described by Lounatmaa (1985). Preparations were observed by transmission electron microscopy.

Enzyme activity. Enzyme activities were determined in two commercial systems, API ZYM (Analytab Products) and Rapid-ANA (Innovative Diagnostic Systems), following the manufacturers' recommended methods.

Dehydrogenase assays. Cells were grown for approximately $48 \mathrm{~h}$ in Brucella broth (Difco) with haemin $\left(5.0 \mathrm{mg} \mathrm{l}^{-1}\right)$ and vitamin $\mathrm{K}_{1}\left(5 \mathrm{mg} \mathrm{m}^{-1}\right)$, with the addition of $1 \%(\mathrm{w} / \mathrm{v})$ pyruvate for strains of Bilophila. Cells were harvested by centrifugation at $12000 \mathrm{~g}$ in a Sorvall RC 5B centrifuge for $20 \mathrm{~min}$ and resuspended in $0 \cdot 1 \mathrm{M}-\mathrm{HEPES} /$ $\mathrm{NaOH}(\mathrm{pH} 7.5$ ). Cells were passed three times through a French pressure cell (SLM Instruments) at 12000 p.s.i. $(\sim 83 \mathrm{MPa}$ ) and the resulting suspension was centrifuged at $37000 \mathrm{~g}$ for $15 \mathrm{~min}$. Either $7.5 \mu \mathrm{g}$ of protein (for Bacteroides fragilis group isolates) or up to $30 \mu \mathrm{g}$ (for Bilophila isolates) of cell extract was subjected to polyacrylamide gel electrophoresis (PAGE) according to published procedures (Laemmli \& Favre, 1973) in a $10 \%$ $(w / v)$ running gel with the following modifications: SDS was eliminated from all buffers, $\beta$-mercaptoethanol was eliminated from the sample buffer, and the samples were not boiled. Staining was carried out according to published procedures: malate dehydrogenase (Williams et al., 1975), glutamate dehydrogenase (Gharbia \& Shah, 1988) and glucose-6-phosphate dehydrogenase (Fildes \& Parr, 1963).

\section{RESULTS AND DISCUSSION}

Biochemical and morphological characterization. All strains were able to grow in and were usually stimulated by the presence of $20 \%(\mathrm{v} / \mathrm{v})$ bile. They were all strongly catalase-positive with $15 \%(\mathrm{v} / \mathrm{v}) \mathrm{H}_{2} \mathrm{O}_{2}$, able to reduce nitrate (occasionally to $\mathrm{N}_{2}$ ), non-motile, indole-negative, non-sporeforming, obligately anaerobic Gram-negative bacilli, $0 \cdot 7-1 \cdot 1 \mu \mathrm{m}$ wide by $1.0-10.0 \mu \mathrm{m}$ long (Fig. 1). Most strains were urease positive. Colonies appeared on BBE agar after $4 \mathrm{~d}$, either as irregular, low convex, black, opaque colonies $1-2 \mathrm{~mm}$ in diameter or as erose, circular, umbonate, translucent colonies with dark black centres. On Brucella agar after $4 \mathrm{~d}$, colonies were circular, erose, $0.6-0.8 \mathrm{~mm}$ in diameter, raised, translucent and grey. At times, growth was not evident until after $7 \mathrm{~d}$ of incubation. Cells were very pleomorphic, with swollen portions and irregular walls; often cells appeared to have lighter-staining areas. Flagella were not seen.

All strains produced $\mathrm{H}_{2} \mathrm{~S}$ in SIM medium. Growth in broth media was stimulated by $20 \%$ bile and $1 \%$ pyruvate but not by formate plus fumarate, or by arginine, sodium bicarbonate, 


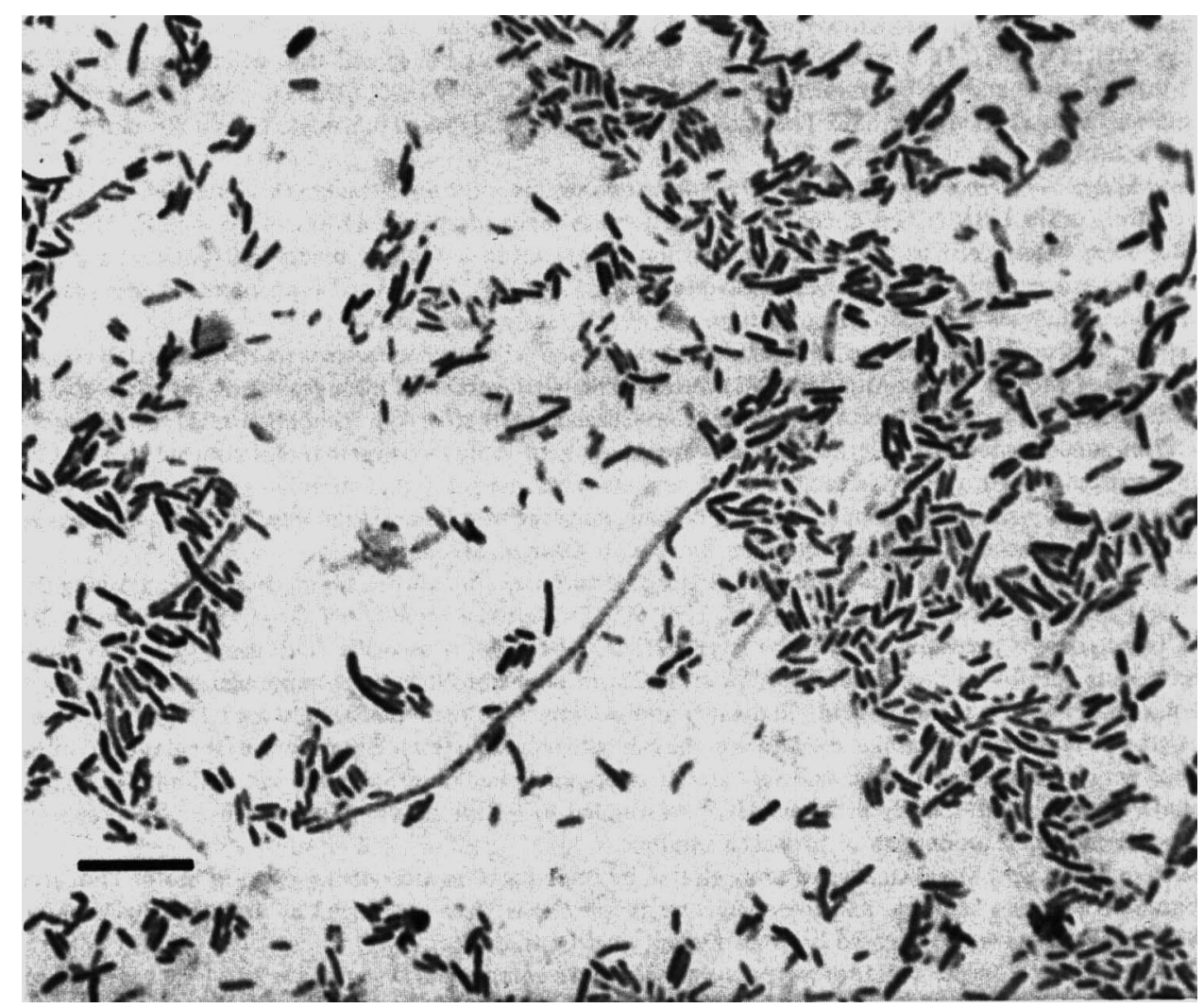

Fig. 1. Gram-stained smear of Bilophila wadsworthia from colonies grown on BBE agar, showing pleomorphic, unevenly staining bacilli. Bar, $10 \mu \mathrm{m}$.

magnesium sulphate, haemin or rabbit serum. All strains were asaccharolytic, gelatinasenegative, showed no reaction in PRAS milk, were unable to hydrolyse starch or aesculin, and were lecithinase- and lipase-negative. Occasional strains were weakly desulphoviridin-positive, although no strains were found to reduce sulphate. All strains exhibited zones of inhibition surrounding the special-potency kanamycin and colistin disks but were resistant to the vancomycin disk. Strains did not produce a $\beta$-lactamase, as determined by the absence of hydrolysis of nitrocefin.

All strains tested produced major amounts of acetic acid and sometimes minor to trace amounts of succinic acid from growth in pyruvate-supplemented PRAS peptone-yeast and petone-yeast-glucose broths. Lactic acid was not detected. As observed with Desulfomonas, magnesium sulphate increased the production of acetate from pyruvate and stimulated growth in media containing pyruvate. For this reason, and because some strains were weakly positive in the desulphoviridin test, we used type strains of Desulfomonas and Desulfovibrio as controls in several comparison studies.

Electron microscopy. No flagella or other appendages were observed on negatively stained cells. Thin-section and freeze-fractured preparations revealed the cell envelope structures of a Gram-negative bacterium. A detailed electron microscopy study by $\mathrm{K}$. Lounatmaa and coworkers will be published elsewhere.

Nucleic acid studies. The dot-blot procedure utilizing whole-cell chromosomal DNA detects homology at approximately the $30 \%$ level (Roberts et al., 1987) and can thus be used as a crude estimation of relatedness. In a previous study, 27 Bacteroides species (none of which shared more than $30 \%$ DNA homology with any other species examined) showed no homology with each 
other by this dot-blot procedure (Roberts et al., 1987). Preliminary dot-blots with the organism described here (Bilophila: see below) showed strong homology among all strains of Bilophila tested and no homology with Desulfomonas pigra or Desulfovibrio desulfuricans. Additional dotblots of two selected strains of the novel organism (WAL 7781 and WAL 7959) against the ATCC type strains listed in Methods revealed slight homology of Bacteroides vulgatus with both Bilophila strains. This homology, which appeared to be slightly stronger than that exhibited among members of the Bacteroides fragilis group, suggested that there may be some genetic relationship between Bilophila and Bacteroides vulgatus.

Thermal melting profiles from strains WAL 7959 and WAL 7781 indicated identical G + C contents of 39-40 mol \%. Published results for Bacteroides vulgatus are 40-42\% G $+\mathrm{C}$ (Johnson \& Ault, 1978).

Cellular fatty acid composition. The Bilophila strains showed a cellular fatty acid composition of

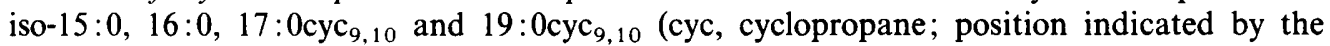
subscript numbers). Bacteroides fragilis group strains tested concurrently showed major amounts of anteiso-15:0 and Desulfomonas pigra yielded only iso-15:0 and 16:0 fatty acids in major amounts. The presence of both iso-15:0 fatty acids and $17: 0$ and $19: 0$ cyclopropanes within the same organism is unique among 270 species groups of anaerobes currently included in the Microbial ID data base (although it should be noted that fatty acid composition can vary markedly with culture conditions and phase of growth) and further supports the inclusion of these strains in a new genus.

Enzyme activity. Limited numbers of strains of Bilophila tested by the API ZYM system showed very weak positive results for lipase esterase (C8) and weak to strong reactions for acid phosphatase. Tests for esterase (C4) activity were variable. There were no positive reactions by any strain tested in the RapID ANA system.

Dehydrogenase studies. No dehydrogenase bands were seen for Bilophila strains tested. $B$. fragilis group and enzyme controls were positive for malate dehydrogenase, glutamate dehydrogenase and glucose-6-phosphate dehydrogenase (results not shown).

Two major studies of faecal flora composition have recovered Bacteroides fragilis group, Eubacterium spp., Fusobacterium spp., Peptostreptococcus spp. and Coprococcus as predominant species among North American and Japanese-American males (Holdeman et al., 1976; Moore \& Holdeman, 1974). These studies also described numerous strains that did not fit any existing species designations. None of the previously undescribed species was similar to the organism described here in that all were nitrate- and catalase-negative and some differed in other respects as well.

The Bacteroides fragilis group, a major component of the gastrointestinal flora, is characterized by saccharolytic fermentation of carbohydrates, production of succinic and acetic acids as metabolic endproducts of glucose fermentation, $40-48 \mathrm{~mol} \% \mathrm{G}+\mathrm{C}$, and a cell wall composition of predominantly anteiso- and iso- methyl branched-chain fatty acids.

Shah \& Collins (1989) have proposed that the genus Bacteroides be restricted to the $B$. fragilis group and related species. Members of this group are recognized in routine microbiological culture of clinical specimens by their ability to grow in the presence of aminoglycosides and $20 \%$ bile, a property exploited in the use of the selective and differential medium, BBE. Most other strictly anaerobic faecal bacteria, with the exceptions of the $B$. fragilis group, the organism described herein, and an occasional Fusobacterium species, are inhibited on this medium. Although the organism described here exhibited some homology with Bacteroides vulgatus in dot-blot assays, it is otherwise quite different from the Bacteroides, particularly in terms of metabolic endproducts (lack of succinic acid production), cell-wall fatty acid composition, and electrophoretic patterns of soluble cellular proteins (unpublished results). Additionally, the cellwall fatty acid composition of this organism is unique among all obligate anaerobes examined with this method.

The unique characteristics of this organism prompted the proposal for a new genus, i.e. Bilophila. This genus is most similar to those within the family Bacteroidaceae, which includes 
other anaerobic, rod-shaped, Gram-negative bacilli that are not inhibited by $20 \%$ bile. Since only one homologous group of organisms has been characterized, the name wadsworthia is proposed for this species.

\section{Description of Bilophila gen. nov.}

\section{bil.o'phil.a. ML adj. bilophila, bile-loving}

Cells (from colonies grown on Brucella blood agar) are Gram-negative, non-motile, nonsporeforming, pleomorphic rods with swollen ends, vacuole-like pale areas, and variable uptake of stain. Cells are $0 \cdot 7-1 \cdot 1 \mu \mathrm{m}$ wide and $1-10 \mu \mathrm{m}$ long. Cells from colonies grown on BBE agar are smaller and more regular. Colonies on Brucella agar after $4 \mathrm{~d}$ incubation are $0.6-0.8 \mathrm{~mm}$ in diameter, raised, erose, circular or slightly irregular, grey, translucent, and may be slightly spreading at the edges, similar to those of some strains of Bacteroides ureolyticus. The organism is obligately anaerobic.

Growth is stimulated by bile and pyruvate. Nitrate is reduced to nitrite and occasionally to $\mathrm{N}_{2}$, hydrogen sulphide is produced, and abundant catalase is produced. Oxidase is not produced, gelatin is not liquefied, skim milk is not changed, neither starch nor aesculin is hydrolysed, and neither lecithinase nor lipase is produced. Desulphoviridin is weakly present in some strains; sulphate is not reduced. The organisms are non-saccharolytic; fermentation products from peptone-yeast broth with pyruvate include major amounts of acetic acid and variable minor amounts of succinic and lactic acids. Acid phosphatase is produced in variable amounts at $35^{\circ} \mathrm{C}$.

The G + C content of the two strains tested (WAL 7781 and 7959) ranges from 39 to $40 \mathrm{~mol} \%$, as determined by the thermal melting method. Cellular fatty acids include iso-15:0, 16:0, $17: 0$ cyc $_{9,10}$ and $19: 0$ cyc $_{9,10}$ (cyc, cyclopropane).

The organism was isolated from gangrenous, perforated, inflamed and non-inflamed appendices, and also from normal human faeces. The type species is Bilophila wadsworthia.

Description of Bilophila wadsworthia sp. nov.

wads.wor'th.i.a. ML adj. wadsworthia, from the Wadsworth Anaerobe Laboratory; named after the Wadsworth Veterans' Administration Medical Center, where the organism was first described.

Cells (from colonies grown on Brucella blood agar) are Gram-negative, non-motile, nonsporeforming, pleomorphic rods with swollen ends, vacuole-like pale areas, and variable uptake of stain. Cells are $0 \cdot 7-1 \cdot 1 \mu \mathrm{m}$ wide and $1-10 \mu \mathrm{m}$ long. The cells are smaller and more regular from colonies grown on BBE agar.

Other characteristics of the species are identical to those described for the genus, with the additional characteristic of the production of ammonia from urea. The type strain is WAL 7959, which has been deposited with the American Type Culture Collection, Rockville, MD, USA (ATCC 49260). Its $\mathrm{G}+\mathrm{C}$ content is 39 to $40 \mathrm{~mol} \%$.

Support for these studies was provided by a grant from Smith, Kline \& French Laboratories and by Veterans' Administration Merit Review Funds awarded to S.M.F.

\section{REFERENCES}

Bennion, R. S., Baron, E. J., Thompson, J. E., Downes, J., Summanen, P. \& Finegold, S. M. (1989). The bacteriology of gangrenous and perforated appendicitis - revisited. Annals of Surgery (in the Press).

Berne, T. V., Yellin, A. W., Appleman, M. D. \& Heseltine, P. N. R. (1982). Antibiotic management of surgically treated gangrenous or perforated appendicitis. American Journal of Surgery 144, 8-13.

David, I. B., Buck, J. R. \& FIlleR, R. M. (1982). Rational use of antibiotics for perforated appendicitis in childhood. Journal of Pediatric Surgery 17, 494-500.
Fildes, R. A. \& PARR, C. W. (1963). Starch-gel electrophoresis of red cell glucose-6-phosphate dehydrogenase. Biochemical Journal 87, 45p.

Finegold, S. M. (1977). Anaerobic Bacteria in Human Disease. New York: Academic Press.

Finegold, S. M., AtTebury, H. R. \& Sutter, V. L. (1974). Effect of diet on human fecal flora: comparison of Japanese and American diets. American Journal of Clinical Nutrition 27, 1456-1469.

Gharbia, S. E. \& ShaH, H. M. (1988). Characteristics of glutamate dehydrogenase, a new diagnostic marker for the genus Fusobacterium. Journal of General Microbiology 134, 327-332. 
Holdeman, L. V., Good, I. J. \& Moore, W. E. (1976). Human fecal flora: variation in bacterial composition within individuals and a possible effect of emotional stress. Applied and Environmental Microbiology 31, 359-375.

holdeman, L. V., Cato, E. P. \& Moore, W. E. C. (editors) (1977). Anaerobe Laboratory Manual, 4th edn. Blacksburg, Virginia: Virginia Polytechnic Institute and State University.

holdeman, L. V., Cato, E. P. \& Moore, W. E. C. (1984). Taxonomy of anaerobes: present state of the art. Reviews of Infectious Diseases 6 (suppl. 1), S1-S10.

JoHNSON, J. L. (1981). Genetic characterization. In Manual of Methods for General Bacteriology, pp. 457-458. Edited by P. Gerhardt, R. G. E. Murray, R. N. Costilow, E. W. Nester, W. A. Wood, N. R. Krieg \& G. B. Phillips. Washington, DC: American Society for Microbiology.

Johnson, J. L. \& AULT, D. A. (1978). Taxonomy of the Bacteroides. II. Correlation of the phenotypic characteristics with deoxyribonucleic acid homology groupings for Bacteroides fragilis and other saccharolytic Bacteroides species. International Journal of Systematic Bacteriology 28, 257-268.

LAEMMLI, U. K. \& FAVRE, M. (i973). Maturation of the head of bacteriophage T4. I. DNA packaging events. Journal of Molecular Biology 80, 575-599.

Lau, W. Y., Teoh-Chan, C. H., Fan, S. T., Yam, W. C., Lau, K. F. \& Wong, S. H. (1984). The bacteriology and septic complication of patients with appendicitis. Annals of Surgery 200, 576-581.

LoUNATMAA, K. (1985). Electron microscopic methods for the study of bacterial surface structures. In Enterobacterial Surface Antigens: Methods for Molecular Characterisation, pp. 243-261. Edited by T. K. Korhonen, E. A. Dawes \& P. H. Makela. Amsterdam: Elsevier.

MOORE, W. E. \& Holdeman, L. V. (1974). Human fecal flora: the normal flora of 20 JapaneseHawaiians. Applied Microbiology 27, 961-979.
Moss, C. W. \& NunEz-MoNTIEL, O. I. (1982). Analysis of short-chain acids from bacteria by gas-liquid chromatography with fused-silica capillary column. Journal of Clinical Microbiology 15, 308-311.

Pieper, R., Kager, L., Lindberg, A. A. \& Nord, C. E. (1979). Acute appendicitis and Bacteroides fragilis. Scandinavian Journal of Infectious Diseases (Supplement) 19, 92-97.

Roberts, M. C., Moncla, B. \& KenNy, G. E. (1987). Chromosomal DNA probes for identification of Bacteroides species. Journal of General Microbiology 133, 1423-1430.

Shah, H. N. \& Collins, M. D. (1989). Proposal to restrict the genus Bacteroides (Castellani and Chalmers) to Bacteroides fragilis and closely related species. International Journal of Systematic Bacteriology 39, 85-87.

SPIEGEL, C. A. \& RoBerTs, M. (1984). Mobiluncus gen. nov., Mobiluncus curtisii subsp. curtisii sp. nov., Mobiluncus curtisii subsp. holmesii subsp. nov. and Mobiluncus mulieris sp. nov., curved rods from the human vagina. International Journal of Systematic Bacteriology 34, 177-184.

Sutter, V. L., Citron, D. M., Edelstein, M. A. C. \& FINEGOLD, S. M. (1985). Wadsworth Anaerobic Bacteriology Manual, 4th edn. Belmont, California: Star Publishing Co.

Werner, H. \& Seeliger, H. P. R. (1963). Kulturelle Untersuchungen über den Keimgehalt der Appendix unter besonderer Berucksichtigung der Anaerobier. Zentralblatt für Bakteriologie, Parasitenkunde, Infectionskrankheiten und Hygiene 188, 345364.

Williams, R. A. D., Bowden, G. H., HaRdie, J. M. \& SHAH, H. (1975). Biochemical properties of Bacteroides melaninogenicus subspecies. International Journal of Systematic Bacteriology 25, 298-300. 